\title{
Hyperviscosity in the Newborn Lamb Produces Pertubation in Glucose Homeostasis
}

\author{
JAMES S. CRESWELL, DAVID WARBURTON, JOHN B. SUSA, RICHARD M. COWETT, and \\ WILLIAM $\mathrm{OH}^{(15)}$ \\ Department of Pediatrics, Women and Infants Hospital of Rhode Island, and Brown University Program in Medicine, \\ Providence, Rhode Island, USA
}

\begin{abstract}
Summary
We studied the effect of hyperviscosity on plasma glucose concentration, endogenous glucose production, and plasma insulin concentration in 12 term mixed breed newborn lambs. After a 7-hr fast, $0.45 \%$ saline was infused at a constant rate for $6 \mathrm{hr}$ during which time hourly plasma glucose and 3-hourly plasma insulin concentrations were determined. A glucose turnover determination by the prime-constant infusion technique using ${ }^{3} \mathrm{H}_{6}$ radiolabeled glucose was performed at a steady state. An exchange transfusion was then carried out using maternal packed red blood cells in six lambs to produce hyperviscosity and using maternal whole blood in six other lambs to maintain normoviscosity. After the exchange transfusion, a second study identical to that in the pre-exchange period was carried out. There was no significant difference in the mean plasma glucose concentration $(\mathrm{mg} / \mathrm{dl}$; mean \pm S.E.) between groups during the first turnover period (pre-exchange transfusion) $[103 \pm 4.9$ (Normoviscous) versus $96 \pm 4.8$ (Hyperviscous) ], but during the postexchange transfusion turnover period, the plasma glucose concentration was lower in the hyperviscous than in the normoviscous group $[89 \pm 4.3$ (Normoviscous) versus $76 \pm 4.0$ (Hyperviscous)] $(P<0.05$.) Endogenous glucose production declined from the first to the second glucose turnover determination in both groups, but there was no significant difference between the normoviscous and hyperviscous groups. Plasma insulin concentrations were similarly low in both groups suggesting suppression in the fasted state. The data suggest that the hyperviscosity acts as an independent variable to depress plasma glucose concentration, the mechanism of which is still undefined.
\end{abstract}

Hypoglycemia in newborn infants is frequently observed in association with hyperviscosity. However, in at least two clinical conditions that are associated with both neonatal hypoglycemia and hyperviscosity, there are etiologic factors which may lead to hypoglycemia independent of hyperviscosity. In the infant of the diabetic mother, a state of "functional hyperinsulinism" may account for hypoglycemia independent of hyperviscosity (2); in small-for-gestational age infants, depletion of glycogen reserves (9) and functional depression of hepatic gluconeogenesis (13) are known causes of increased incidence of hypoglycemia. It is therefore not clear whether hyperviscosity is indeed a direct cause of hypoglycemia in these high-risk infants. Furthermore, cyanotic congenital heart disease is known to be associated with polycythemia (14); it is also of clinical relevance to determine if polycythemia may in itself influence glucose homeostasis in such clinical situations. Thus, the purpose of this study was to determine whether polycythemia and hyperviscosity itself are independent variables in relationship to depression of plasma glucose concentration. We have developed a hyperviscous animal model in the newborn lamb and have utilized it to study changes in plasma glucose concentration, endogenous glucose production, and plasma insulin concentration under hyperviscous conditions.

\section{MATERIALS AND METHODS}

Twelve mixed breed term newborn lambs were the subjects of the study and were evenly divided into control and experimental groups. The two groups were similar in age (mean \pm S.D.; $4.3 \pm$ 1.0 days in the hyperviscous group and $4.6 \pm 1.2$ days in the normoviscous group) and weight (5.4 $\pm 0.4 \mathrm{~kg}$ in the hyperviscous group and $5.3 \pm 0.7 \mathrm{~kg}$ in the normoviscous group.) All were delivered spontaneously and fed by their mothers ad libitum before initiation of the study. At 4 to 5 days of age, the glucose homeostatic mechanism of lambs is well established; it assured the steady state condition before the experimental manipulation for the current investigation.

Seven $\mathrm{hr}$ before the initiation of the study, the lambs were separated from their mothers and fasted. The lambs were blindfolded, and under light restraint and local anesthesia, the external jugular vein and internal carotid artery were catheterized using No. 5 French polyethylene catheters (Sherwood Medical, St. Louis, MO) and the study protocol as shown in schematic form in Figure 1 was carried out.

Thirty min after the catheterization procedure, an infusion of $0.45 \%$ saline at $0.06 \mathrm{ml} / \mathrm{kg} / \mathrm{min}$ was begun and continued through the end of the turnover period. Glucose was obtained at time 0 and hourly during the $6 \mathrm{hr}$ equilibration period and then $0,30,60$, $70,80,90,100$ and $110 \mathrm{~min}$ of the turnover period to demonstrate the steady state of plasma glucose concentration. Blood for plasma insulin concentration and blood viscosity determination was obtained at 0,3 , and $6 \mathrm{hr}$ of the equilibration period and at the end of the turnover period. After $6 \mathrm{hr}$ of equilibration period a 12.5 $\mu \mathrm{Ci} / \mathrm{kg}$ bolus ${ }^{3} \mathbf{H}_{6}$ glucose (New England Nuclear Corp., Boston, MA) was infused, followed by a 110 -min constant infusion of 12.5 $\mu \mathrm{Ci} / \mathrm{kg}{ }^{3} \mathrm{H}_{6}$ glucose in $0.45 \%$ saline at the same constant rate. During the equilibration and turnover periods, glucose steady state, defined as plasma glucose concentration values $\pm 10 \mathrm{mg} / \mathrm{dl}$ from the mean, was achieved.

After the completion of the first turnover period, an exchange transfusion was carried out using maternal blood obtained percutaneously from an external jugular vein the morning of the study and stored at $4^{\circ} \mathrm{C}$ in heparinized blood storage bags (Fenwall Laboratories, Deerfield, IL). In the hyperviscous group, packed maternal red blood cells (hematocrit, 75 to $85 \%$ ) were used for the exchange transfusion, and in the normoviscous group maternal whole blood (hematocrit, 25 to $35 \%$ ) was used. In both cases, the volume of the exchange transfusion was $75 \mathrm{ml} / \mathrm{kg}$. The duration of the exchange transfusion was a mean of $65 \mathrm{~min}$ (range, 50 to $100 \mathrm{~min}$ ). Thirty min after the completion of the exchange transfusion, an identical $6 \mathrm{hr}$ equilibration period and glucose turnover period was carried out with blood samples obtained for analyses identical to pre-exchange period as shown in Figure 1.

Plasma glucose was determined by the glucose oxidase method on a glucose analyzer (model 23A Glucose Analyzer; Yellow Springs Instrument Company, Yellow Springs, $\mathrm{OH}$ ), insulin by radioimmunoassay method of Hales and Randle (6), and blood 


\section{STUDY PROTOCOL}

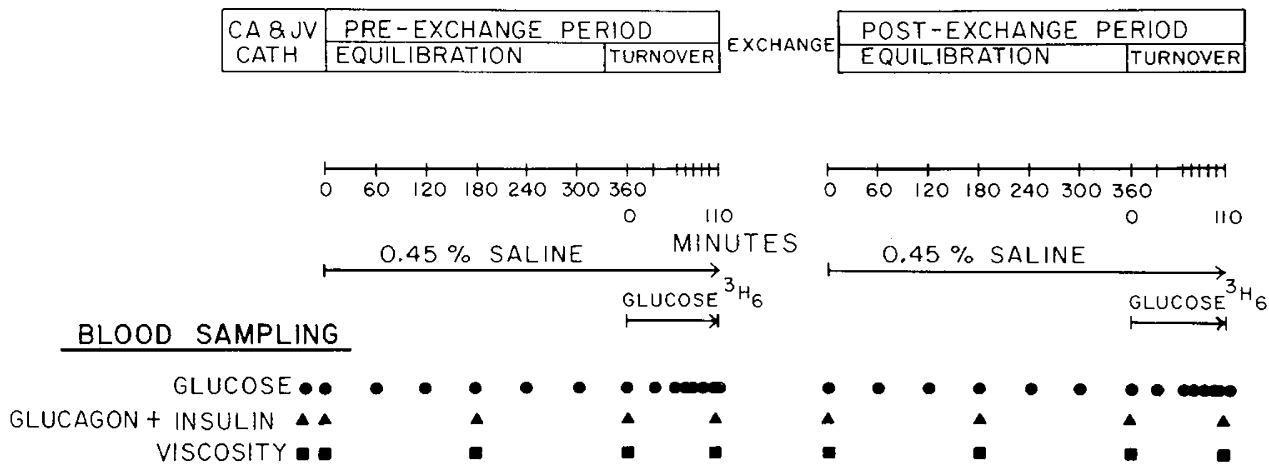

Fig. 1. Schematic presentation of study protocol.

WHOLE BLOOD VISCOSITY

(CENTIPOISE AT SHEAR RATE OF $22.5 \mathrm{Sec}^{-1}$ )

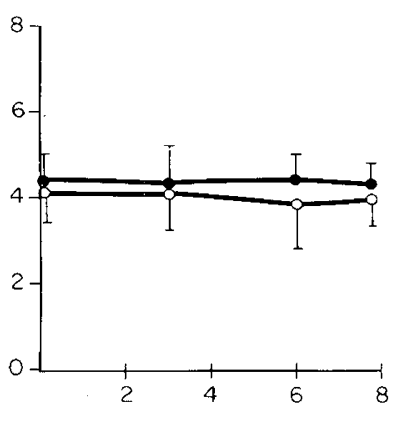

PRE-EXCHANGE PERIOD

TIME (Hours)

Fig. 2. Changes in blood viscosity after exchange transfusion.

viscosity by Wells-Brookfield Micro-Viscometer (12) (Brookfield Laboratory, Stanton, MA). Endogenous glucose production was deetermined as previously described $(3,11)$, and metabolic clearance rates for glucose were calculated by the standard formula using data from plasma glucose concentration and endogenous glucose production.

Paried $t$ test was used for statistical analysis within groups when comparing values between pre- and postexchange transfusion and Student $t$ test for comparison between the two groups during preor postexchange transfusion period.

\section{RESULTS}

As shown in Figure 2, the blood viscosities in the two groups were similar during the pre-exchange period. The postexchange blood viscosity of the normoviscous group was unchanged, whereas in the hyperviscous group the viscosity was significantly increased demonstrating the success of raising whole blood viscosity with packed red cell transfusion. The plasma glucose concentration in the normoviscous group was similar to the hyperviscous group during the 6-hr pre-exchange period ranging in values from 95 to $120 \mathrm{mg} / \mathrm{dl}$. A steady state was also observed because the blood glucose concentration measured at hourly intervals for $6 \mathrm{hr}$ before turnover study (see Fig. 1) were within 10\% of the mean values. During the postexchange period, the plasma glucose concentration of the hyperviscous group was significantly lower throughout the 6-hr equilibration period.

Table 1 shows the mean plasma glucose values during the turnover periods. The values were similar between normoviscous and hyperviscous group during the pre-exchange period, but a
Table 1. Plasma glucose concentration during turnover study periods

\begin{tabular}{lccc}
\hline & \multicolumn{3}{c}{ Plasma glucose $(\mathrm{mg} / \mathrm{dl})$} \\
\cline { 2 - 4 } Period & Pre-exchange & Postexchange & $p$ \\
\hline $\begin{array}{c}\text { Normoviscous } \\
(n=6)\end{array}$ & $103 \pm 4.9^{1}$ & $89 \pm 4.3$ & $<0.05$ \\
$\begin{array}{c}\text { Hyperviscous } \\
(n=6)\end{array}$ & $96 \pm 4.8$ & $76 \pm 4.0$ & $<0.01$ \\
$P \quad$ n.s. & $<0.05$ & \\
\hline
\end{tabular}

${ }^{1}$ Mean \pm S.E.

Table 2. Plasma insulin, glucose metabolic clearance, and endogenous glucose production rates in study lambs

\begin{tabular}{|c|c|c|c|}
\hline & & $\begin{array}{l}\text { Pre-exchange } \\
\text { period }\end{array}$ & $\begin{array}{c}\text { Postexchange } \\
\text { period }\end{array}$ \\
\hline Insulin $(\mu \mathrm{U} / \mathrm{ml})$ & $\begin{array}{l}\text { Normoviscous } \\
\text { Hyperviscous }\end{array}$ & $\begin{array}{l}15.4 \pm 3.7^{1} \\
11.6 \pm 2.9\end{array}$ & $\begin{array}{l}7.7 \pm 2.3 \\
9.4 \pm 2.0\end{array}$ \\
\hline $\begin{array}{l}\text { Glucose metabolic } \\
\text { clearance (ml/ } \\
\mathrm{kg} / \mathrm{min})\end{array}$ & $\begin{array}{l}\text { Normoviscous } \\
\text { Hyperviscous }\end{array}$ & $\begin{array}{l}6.3 \pm 0.7 \\
6.0 \pm 0.8\end{array}$ & $\begin{array}{l}5.7 \pm 0.5 \\
4.7 \pm 0.8\end{array}$ \\
\hline $\begin{array}{l}\text { Endogenous glu- } \\
\text { cose production } \\
(\mathrm{mg} / \mathrm{kg} / \mathrm{min})\end{array}$ & $\begin{array}{l}\text { Normoviscous } \\
\text { Hyperviscous }\end{array}$ & $\begin{array}{l}6.6 \pm 0.8 \\
5.7 \pm 0.8\end{array}$ & $\begin{array}{l}5.0 \pm 0.5^{2} \\
3.6 \pm 0.7^{2}\end{array}$ \\
\hline
\end{tabular}

significant difference was observed between pre-exchange and postexchange periods in the normoviscous and hyperviscous groups during the post exchange periods.

As shown in Table 2, plasma insulin levels were similarly low in both groups, and no differences were observed before or after the exchange transfusion. The metabolic clearance rates for glucose were not significantly different between the two groups during the pre- or postexchange turnover periods. The endogenous glucose production rate declined significantly from pre- to postexchange transfusion periods for both groups, but no significant difference was observed between the two groups during the post exchange transfusion period.

\section{DISCUSSION}

The observed reduction in plasma glucose concentration and endogenous glucose production rate during the postexchange turn- 
over periods in both normoviscous and hyperviscous lambs are accountable by the effect of fasting these lambs during the 18- to $20-\mathrm{hr}$ study periods. However, the significant difference in plasma glucose values during the postexchange periods between the normoviscous and hyperviscous lamb suggests that hyperviscosity itself may further produce an effect that results in lowering of the plasma glucose concentration. This observation could be spurious on the basis of a lower glucose content in the donor packed cell blood used in the exchange transfusion of the hyperviscous model; however, arithmetic calculation shows that the difference in glucose content (approximately $35 \mathrm{mg} / 100 \mathrm{ml}$ ) between packed and whole blood is far from adequate to account for the difference in plasma glucose values between the two groups on the basis of dilution. Another technical point that might account for the suppression of plasma glucose values independent of hyperviscosity is the fact that the blood utilized for exchange transfusion (to induce hyperviscosity) was collected in heparinized solution and stored to $4^{\circ} \mathrm{C}$ for 4 to $6 \mathrm{hr}$. It is conceivable during these 4 to $6 \mathrm{hr}$ storage time that erythrocyte glycolysis may take place, resulting in reduction or depletion of intraerythrocytic glucose. These glucose "depleted" erythrocytes may have a higher glucose utilization rate, thus resulting in lower plasma glucose values in the hyperviscous group on the basis of a larger red cell volume than the normoviscous group. However, it has long been known that glycolysis in the sheep erythrocyte is somewhat slower than in other species (10). We also measured glucose in blood, in plasma, and in a lysed red cell preparation in hyperviscous (packed to $75 \%$ hematocrit) and normoviscous ( $25 \%$ hematocrit) blood before, and hourly during an $8-\mathrm{hr}$ storage at $4^{\circ} \mathrm{C}$. The result showed no change in glucose concentration in blood, plasma, and lysed cells throughout the 8 -hr period $(n=6)$ both in hyperviscous and normoviscous preparations. Thus, this technical explanation would appear remote.

Endogenous glucose production declined significantly in both groups from pre- to postexchange transfusion periods probably as a result of prolonged fasting. There was no significant difference in endogenous glucose production rate between hyperviscous and normoviscous groups during the postexchange periods; this lack of significant difference in endogenous glucose production between the two groups suggests that the lower plasma glucose concentration in the hyperviscous group is due to factors other than reduced glucose production.

Plasma insulin levels were similarly low in both groups during pre- and postexchange periods. It is noted that the timing of sampling for plasma insulin was done at 3 and $6 \mathrm{hr}$ during the equilibration period and at the time of turnover study; one could argue that the sampling time may not reflect the true insulin response to glucose changes. However, during these periods of time the plasma glucose values did not show sudden fluctuation but rather a steady decline in both groups (more so in hyperviscous group). Thus, the plasma insulin values should reflect a change if it were to play a role in the suppression of plasma glucose values in the hyperviscous lambs.

Another potential possibility is that in the hyperviscous state, a reduction in capillary flow rate may allow more time for extraction of glucose by the peripheral tissue thus leading to decreased plasma glucose on the basis of increased utilization. Our data on metabolic clearance rate for glucose were slightly lower in the hyperviscous group during the postexchange period; however, perhaps because of small numbers, the difference was not statistically different from the normoviscous group. Thus, our data did not clearly define the reason for the suppression of plasma glucose in the hyperviscous state.

It is known that neonatal hyperviscosity may manifest as pleth- ora, cyanosis, respiratory distress (4), congestive heart failure (8), central nervous system manifestations (4), necrotizing enterocolitis (7), depression of renal function (1), and hypolgycemia (6). In the infant of the diabetic mother and in the small-for-gestational age infant, increased incidence in hyperviscosity and hypoglycemia are known; however, the disturbance in glucose homeostasis in these instances may be related to the primary conditions (diabetes and fetal growth retardation) during pregnancy (1) and may not be related to hyperviscosity. In this study, hyperviscosity as produced in our model did lead to reduction in plasma glucose concentration during the turnover period which suggests that hyperviscosity itself may play a role in the observed suppression of plasma glucose concentration.

\section{CONCLUSION}

Hyperviscosity as produced in an experimental model in the newborn lamb leads to depression of plasma glucose concentration. The mean plasma glucose values in the hyperviscous model were lower than in the normoviscous group after exchange transfusion with packed red cells ( $76 \pm 4$ versus $89 \pm 4.3 \mathrm{mg} / \mathrm{dl}$; mean \pm S.E,$P<0.05$ ). No significant difference in endogenous glucose production $(5.0 \pm 0.5$ versus $3.6 \pm 0.7 \mathrm{mg} / \mathrm{kg} / \mathrm{min})$ and plasma insulin values $7.7 \pm 2.3$ versus $9.4 \pm 2.0 \mu \mathrm{unit} / \mathrm{ml}$ ) were observed between the two groups. Although it is hypothesized that increased peripheral glucose utilization may explain the observed depression of the plasma glucose concentration, this speculation requires further investigation. In the clinical setting, hyperviscosity associated with polycythemia may result in a superimposed effect resulting in depression of plasma glucose concentration.

\section{REFERENCES AND NOTES}

1. Aperia, A., Berrqvist, G., Broberger, O., Thodenius, K., and Zetterstrom, R.: Renal function in newborn infants with high hematocrit values before and after isovolemic hemodilution. Acta Paediatr., 63: 878 (1974).

2. Cornblath, M., and Schwartz, R.: Disorders of carbohydrate metabolism in infancy. (W. B. Saunders Co., Philadelphia, 1976).

3. Cowett, R. M., Susa, J., Oh, W., and Schwartz, R.: Endogenous glucose production during constant glucose infusion in the newborn lamb. Pediatr. Res., 12: 853 (1978).

4. Gross, G. P., Hathaway, W. E., and McGaughey, H. R.: Hyperviscosity in the neonate. J. Pediatr., 83: 1004 (1973).

5. Hakanson, D. O., and Oh, W.: Necrotizing enterocolitis and hyperviscosity in the newborn infant. J. Pediatr., 90: 458 (1977).

6. Hales, C. N., and Randle, P. H.: Immunoassay of insulin with insulin antibody precipitates. Biochem. J., 88: 137 (1963).

7. Haworth, J. C., Dilling, L., and Younoszai, M. K.: Relation of blood glucose to hematocrit, birthweight, and other body measurements in normal and growth retarded newborn infants. Lancet, 2: 907 (1967).

8. Minkowski, A.: Acute cardiac failure in connection with neonatal polycythemia. Biol. Neonate, 4: 61 (1962).

9. Shelly, J. J., and Neligan, G. A.: Neonatal hypoglycemia. Br. Med. Bull., 22: 34 (1966).

10. Somogyi, H.: The distribution of sugar and rate of glycolysis in the blood of some mammals. J. Biol. Chem., 103: 665 (1933).

11. Steele, R., Wall, J. S., deBodo, R. C., and Altszuler, N.: Measurement of size and turnover rate of body glucose pool by the isotope dilution method. Am. J. Physiol., 187: 15 (1956).

12. Wells, R. E., Denton, R., and Merrill, E. W.: Measurement of viscosity of biologic fluids by cone plate viscometer. J. Lab. Clin. Med., 57: 646 (1961).

13. Williams, P. R., Fiser, R. H., Jr., Sperling, M. A., and Oh, W.: Effects of oral alanine feeding on blood glucose, plasma glucagon and insulin concentrations in small-for-gestational-age infants. N. Engl. J. Med., 292: 612 (1975).

14. Wood, J. L.: Plethora in the newborn infant associated with cyanosis and convulsions: a review of postnatal erythropoiesis. J. Pediatr., 54: 143 (1959).

15. Requests for reprints should be addressed to: William Oh, M.D., 50 Maude Street, Providence, RI 02908 (USA).

16. This research was supported in part by Grant HD 11343-01 of the National Institute of Child Health and Human Development, Bethesda, MD.

17. Received for publication July 15, 1980.

18. Accepted for publication February 3, 1981. 